\title{
Prevalence of Common Mental Disorders and Associated Factors among Residents of Jimma Town, Southwest Ethiopia
}

\section{Habtamu Kerebih* and Matiwos Soboka}

Department of Psychiatry, College of Health Science, Jimma University, Ethiopia

\begin{abstract}
Background: Common mental disorders such as anxiety, depression and unexplained somatic symptoms and substance use disorders such as alcohol, khat and cigarette contributes to disability and distress to the population impeding productivity and affecting societal wellbeing. Recognizing this, the current study was conducted to be one input for policy maker's efforts in reforming mental health care among the community in our country.
\end{abstract}

Objective: This study assessed prevalence of common mental disorders and its associated factors among residents of Jimma town, March, 2015.

Methodology: Community based cross sectional study was conducted in March, 2015 in Jimma town using interviewer administered structured questionnaire. A total of 745 residents were selected using multi stage probability sampling technique. Self-Reporting Questionnaire (SRQ) was used to determine the prevalence of common mental disorders. Data was analyzed with SPSS version 20. Binary logistic regression analysis was used for both bivariate and multivariate analysis. Strength of association of the variables was determined using odds ratio and $95 \%$ confidence interval.

Results: From a total of 745 respondents, 729 completed the study from which $380(52.1 \%)$ were females. The prevalence of common mental disorders was $33.6 \%$. Variables such as older age, being female, housewife, unable to read and write, chewing khat and having chronic physical illness were significantly associated with higher prevalence of common mental disorders. While being married in marital status was found to be a protective factor from common mental disorders.

Conclusion: There is a high prevalence of common mental disorders among residents of Jimma town. The risk of common mental disorders was higher in females, housewives, in those who were unable to read and write, in current khat users and in respondents who reported to have chronic physical illness. To improve the mental health status of the community, mental health training has to be given to general health care workers in the country. By doing so, appropriate intervention will be taken on factors contributing to common mental disorders.

Keywords: Common mental disorders; Prevalence; Mental illness; Residents

\section{Introduction}

Mental disorders are a global public health agenda and about $14 \%$ of the global burden of disease has been attributed to neuropsychiatric disorders, mostly due to the chronically disabling nature of depression, other common mental disorders and substance use disorders. This is expected to rise to $15 \%$ by the year 2020 which would make the disorders the second leading cause of health disability worldwide. Unipolar depressive disorders alone lead to $12.15 \%$ of years lived with disability, and rank as the third leading contributor to the global burden of diseases. More than 150 million persons suffer from depression at any point in time and nearly 1 million commit suicide every year. Four of the six leading causes of years lived with disability are due to neuropsychiatric disorders (depression, alcohol-use disorders, schizophrenia and bipolar disorder). More than 90 million suffer from an alcohol or other substance use disorders $[1,2]$.

The burden will be the worst in low and middle income countries where the impact of poverty and other communicable diseases are highly rampant. According to projections in 2030 depression will be the leading cause of disability globally accounting for approximately $6 \%$ of the total disability [3].

Community based surveys across the world revealed that the prevalence of common mental disorders among the general populations is very high. In the United States (US) national Comorbidity survey, lifetime prevalence of mood and anxiety disorders was $20.8 \%$ and
$28.8 \%$, respectively [4]. Twelve-month prevalence estimates of mood and anxiety range from $6.6 \%$ to $18.1 \%$ across surveys from Australia and the US community [5]. In the European countries such as Greece and Sweden the magnitude of common mental disorders is high ranging from $14-17.2 \%$ while in eastern Asia the prevalence is around $8.8 \%[6-8]$.

Population based surveys in Africa generally showed higher prevalence of common mental disorder among the community from $10.8 \%$ in Kenya to $34.9 \%$ in South Africa. Whereas, a $12.1 \%$ of life time prevalence and $5.8 \%$ of 12 month prevalence of common mental disorders (CMDs) was shown in Nigeria [9-11]. Available community based studies in Ethiopia conducted in Butajira, Addis Ababa and Kombolcha town indicated that, common mental disorders are the highest ranging from $17 \%-32.4 \%$ [12-14].

Considering the world wide and local prevalence, the impact of

*Corresponding author: Habtamu Kerebih, Department of Psychiatry, College of Health Science, Jimma University, Ethiopia, Tel: +251924316221; E-mail: habtishk@gmail.com

Received March 26, 2016; Accepted June 09, 2016; Published June 16, 2016

Citation: Kerebih H, Soboka M (2016) Prevalence of Common Mental Disorders and Associated Factors among Residents of Jimma Town, Southwest Ethiopia. J Psychiatry 19: 373 doi:10.4172/2378-5756.1000373

Copyright: $\odot 2016$ Kerebih H, et al. This is an open-access article distributed under the terms of the Creative Commons Attribution License, which permits unrestricted use, distribution, and reproduction in any medium, provided the original author and source are credited. 
mental ill health on economic growth is immense to the individual and families putting them into poverty and hindering development. Poverty associated with the direct cost of mental disorders such as mental health care costs and indirectly through the value of the output lost because of inability to work due to the illness affects the economic progress of the community and the nation at large [15].

In addition to the suffering from the illness, people with mental disorders are physically and sexually abused, stigmatized and discriminated on the right to work and education [16]. The connection of common mental disorders with chronic illness and substance use was also explored. Research reports showed that a number of mental disorders, such as depression, anxiety and substance abuse occur in people suffering from chronic non communicable diseases and communicable diseases more than the general population and vice versa. For example, a WHO report indicated that the prevalence of depression in patients with chronic illness, such as hypertension (29\%), diabetes $(27 \%)$, cardiovascular diseases $(31 \%)$, cancer $(33 \%)$, HIV (44\%) and tuberculosis (46\%), is higher [1]. Nearly, $80 \%$ of alcoholic men and women reported temporary symptoms of sadness or anxiety which then progressively became intense and persistent enough to meet criteria for major psychiatric conditions, such as major depressive disorders and anxiety disorders in at least $40 \%$ of the population [17].

In Ethiopia, particularly in Jimma there is a dearth data which assesses the prevalence of common mental disorders among the community residents in association with factors such as substance use disorder, physical chronic illnesses, and social support beyond the socio-demographic and economic information. Therefore, this study assessed prevalence of common mental disorders among residents of Jimma town and associated factors.

\section{Methods}

\section{Study design and settings}

A community based cross-sectional study was conducted in Jimma town, Southwest Ethiopia, from February-March, 2015. Jimma Town is located $352 \mathrm{kms}$ Southwest of Addis Ababa, the capital city of Ethiopia. The town has 17 administrative units (kebeles). The number of households reported in the town was about 32,191 . The total population of Jimma town from 2007 central statistical agency (CSA) census is reported to be 120,960 [18] and with projection rate 4.7, it was estimated that in 2011 the total population to be around 144,369. The town has two hospitals; a general hospital and a University hospital. Psychiatric outpatient and inpatient services are available only at the University hospital.

\section{Population}

The Source populations of the study were residents of Jimma town age $\geq 18$ years during the data collection period. The study population was a sample of adult residents living in Jimma town. Individual residents with hearing impairment and cognitively impaired to consent and unable to recall events were excluded.

\section{Sampling}

A prevalence rate of $32.4 \%$ for common mental disorders from north east Ethiopia, which gave the maximum sample size than prevalence rates found elsewhere in the country, was considered at $95 \%$ certainty and $\pm 5 \%$ margin of error. Considering design effect and adding $10 \%$ non response rate the final sample size was 745 . Two-stage sampling technique was employed for the study. The study unit was housing units with the assumption that each housing unit would have a sampling subject. Using simple random sampling technique, 5 kebeles were selected from the 17 and the number of participants that were selected from each kebele for the study, were determined using proportional allocation of the sample size to the total number of households in each of the selected kebeles. Systematic random sampling technique was employed to select study units. The first study unit was selected randomly between $1^{\text {st }}$ and $\mathrm{k}^{\text {th }}$ and study subjects in every $\mathrm{k}^{\text {th }}$ household were interviewed. When more than one study subjects were found in one household, a lottery method was used to select a participant.

\section{Data collection tools}

A structured interviewer-administered questionnaire was used which has four sub sections: a socio-demographic questionnaire to assess the resident's background information. Self reported questionnaire (SRQ-20), which was developed by WHO, was used to assess the prevalence and presence of CMD. The SRQ was originally designed as self administered scale but was also found to be suitable for interviewer administered questionnaire because of the low literacy rate in developing countries [19]. Each of the 20 items is scored 0 or 1. A score of 1 indicate that the symptom was present during the past month, a score of 0 indicate that the symptom was absent. A cut-off point of 7/8 (7'yes's' a non-case, 8 'yes's' a case) was used which is the most commonly used cut off point in developing countries [20]. It was used in previous community based studies in Ethiopia [12]. In addition, the Oslo 3-items social support scale was used to measure the strength of social support. The scores for the scale range from 3-14. The Oslo-3 scale has been used in several studies, confirming the feasibility and predictive validity with respect to psychological distress. The final section was questionnaire to assess substance use such as khat, alcohol and cigarette together with a questionnaire to assess the presence of chronic physical illnesses such as tuberculosis, cardiovascular diseases, HIV/AIDS, cancer, diabetes, asthma and hypertension. The Amharic version of the questionnaires was used to collect data.

\section{Data collection}

Questionnaire was pre-tested on 5\% residents which were not included in the study to check for applicability and understandability of the instruments. The data collectors and supervisors were trained about the instruments and the process of proper data collection and handling procedures. The supervisors were trained to check for completeness of the questionnaire. Regular supportive supervision was made by the principal investigator. There was cross checking of the data for completeness and for missing value every day among the data collectors and the supervisors.

\section{Operational definitions}

Common mental disorders: Refers to the most prevalent conditions classified under depressive episode, anxiety and somatic symptoms. A score of eight or more in SRQ-20 in the past 4 weeks will be considered as having common mental disorders.

Chronic illness: At least one of seven chronic diseases mentioned: (HIV/AIDS, hypertension, diabetes, any cancer, asthma, hypertension and heart disease, CVD)

Employed: Respondents who are working for governmental or non governmental institutions.

Self-employed: Respondents who are large or small scale merchants are entrepreneurs, work in small scale enterprise and microfinance. 


\begin{tabular}{|c|c|c|c|}
\hline \multicolumn{2}{|c|}{ Characteristics } & Frequency & $\%$ \\
\hline \multirow{2}{*}{ Sex } & Male & 349 & 47.9 \\
\hline & Female & 380 & 52.1 \\
\hline \multirow{5}{*}{ Age } & $18-27$ & 142 & 19.5 \\
\hline & $28-37$ & 303 & 41.6 \\
\hline & $38-47$ & 174 & 23.9 \\
\hline & $48-57$ & 95 & 13 \\
\hline & $>57$ & 15 & 2.1 \\
\hline \multirow{4}{*}{ Religion } & Muslim & 238 & 32.6 \\
\hline & Orthodox & 307 & 42.1 \\
\hline & Protestant & 150 & 20.6 \\
\hline & Others* & 34 & 4.7 \\
\hline \multirow{4}{*}{ Marital status } & Single & 245 & 33.6 \\
\hline & Married & 332 & 45.5 \\
\hline & Divorced and separated & 118 & 16.2 \\
\hline & Widowed & 34 & 4.7 \\
\hline \multirow{5}{*}{ Ethnicity } & Oromo & 267 & 36.6 \\
\hline & Amhara & 208 & 28.5 \\
\hline & Keffa & 149 & 20.4 \\
\hline & Guragie & 73 & 10 \\
\hline & Others" & 32 & 4.4 \\
\hline \multirow{5}{*}{ Educational status } & Unable to read and write & 54 & 7.4 \\
\hline & Able to read and write & 117 & 16 \\
\hline & Primary school & 179 & 24.6 \\
\hline & Secondary school & 212 & 29.1 \\
\hline & College and above & 167 & 22.9 \\
\hline \multirow{6}{*}{ Occupational status } & Employed & 309 & 42.4 \\
\hline & Self employed & 236 & 32.4 \\
\hline & Student & 29 & 4 \\
\hline & Housewife & 56 & 7.7 \\
\hline & Unemployed & 65 & 8.9 \\
\hline & Others" & 34 & 4.7 \\
\hline \multirow{4}{*}{$\begin{array}{l}\text { Gross monthly family } \\
\text { income(ETB) }\end{array}$} & $100-800$ & 217 & 29.8 \\
\hline & $801-1500$ & 156 & 21.4 \\
\hline & $1501-3000$ & 181 & 24.8 \\
\hline & $>3000$ & 175 & 24 \\
\hline \multirow{2}{*}{ Family size } & $<3.6$ & 404 & 55.4 \\
\hline & $>3.6$ & 325 & 44.6 \\
\hline
\end{tabular}

Note: 'Catholic, Jehovah witness and Pagan, "Tigre, Wolayita, Yem, Hadiya and Dawuro, "'Pensioner, Farmer, Daily laborer and House servant

Table 1: Socio-demographic and economic characteristics of study participants in Jimma town, March, $2015(\mathrm{n}=729)$.

Level of social support: For this study social support is measured using Oslo 3-items social support scale with a score of 3-8 indicating poor support, 9-11 moderate support and 12-14 strong support.

Substance use: khat, alcohol and cigarette use in the past one month were used.

\section{Data processing and analysis}

After data was collected, it was coded and entered into a computer using Epi-data version 3.1 programs. Then it was exported to statistical package for social sciences (SPSS version 20). Descriptive statistics: frequency and percentages were calculated and presented in tables. After doing assumption tests in crosstabs (chi square) binary logistic regression analysis was used for both bivariate and multivariate analysis to explore associations and identify independently associated variables with pattern of CMD. This was done by entering each independent variable separately into bivariate analysis. Then, variables with statistical significant association including those variables with $p$-value of less than 0.25 on bivariate analysis were entered into multivariate logistic regression once. Then, variables having $p$-value of less than 0.05 on multiple logistic regressions were finally considered as significantly associated with pattern of CMD. The strength of association of the variables was determined using odds ratio and $95 \%$ confidence level.

\section{Ethical considerations}

The ethical approval was secured from the institutional review board of Jimma University College of Health Sciences. After thoroughly discussing the ultimate purpose and method of the study, a formal written letter was obtained from Jimma town health office and informed verbal consent was obtained from each respondent. The respondents were informed that their inclusion in the study was voluntary and they were informed that they were free to withdraw from the study if they were not willing to participate. If any question they did not want to answer, they were told they had the right to do so. To ensure confidentiality of respondents, their names were left out on the questionnaire. Participants with SRQ-20 score of 7/8 were recommended to consult mental health professionals' help from and those who reported suicidal thoughts were referred to Jimma university Hospital psychiatry clinic.

\section{Results}

\section{Background characteristics of respondents}

From a total of 745 study participants, 729 respondents completed the study yielding $97.8 \%$ response rate. From the 729 study participants, $380(52.1 \%)$ were females. The mean age of the respondents was 36 $( \pm 9.81)$ year with a maximum age of 71 year and minimum of 18 year. The religion of the participants indicated that most were followers of Christian orthodox 307 (42.1) and Muslim 238 (32.6\%) and the majority of them were from Oromo 267 (36.6\%) and Amhara 208 (28.5\%) ethnicity. The majority of respondents were married $332(45.5 \%)$ and many of them of had educational status of secondary school 212 (29.1\%), primary school 179 (24.6\%) and college and above 167 (22.9\%). Majority of them were institutionally employed 309(42.4\%) followed by self-employed 236 (32.4\%). Majority of respondents reported gross monthly family income of 1500-3000 ETB 181 (24.8\%) and $>3000$ ETB 175 (24\%). Family size of study participants showed that more than half, 404(55.4\%), of them had less than 3.6 family members per household (Table 1).

\section{Prevalence of common mental disorder and associated factors}

From all respondents participated in the study 245 (33.6\%) of them had common mental disorders. The pattern of common mental disorders by age showed that as the age increase from 18-27 year to $>57$ year, the prevalence of CMD also increases from 30 (21.1\%)to $9(60.0 \%)$. The percentage of females; $163(42.9 \%)$ affected by CMD were greater than males $82(23.5 \%)$. Majority of respondents who were widowed 21 (61.8\%), separated and divorced $54(45.8 \%)$ and those with lower educational status such as those who were unable to read and write $32(59.3 \%)$ and those who can only read and write $47(40.2 \%)$ had CMD. Large number of respondents with occupational status of housewife 30 (53.6) had high prevalence of CMD. The prevalence of CMD was higher in respondents with family size of $>3.6$ persons per household 133 (40.9\%).

The distributions of CMD among khat users 111 (39.8\%) was higher than non-khat users $134(29.8 \%)$. Alcohol users $64(36.8 \%)$ and cigarette smokers $39(42.4 \%)$ had higher prevalence of CMD than non-alcohol users 181 (32.6\%) and non-cigarette smokers 206 (32.3\%) 
Citation: Kerebih H, Soboka M (2016) Prevalence of Common Mental Disorders and Associated Factors among Residents of Jimma Town, Southwest Ethiopia. J Psychiatry 19: 373 doi:10.4172/2378-5756.1000373

Page 4 of 7

respectively. Majority of respondents with poor social support 137 (41.3\%) and with chronic physical health conditions 76 (48.4\%) had higher prevalence of CMD than with strong social support $7(21.2 \%)$ and those without chronic physical health conditions 169 (29.5\%).
The bivariate logistic regression analysis showed that except religion, alcohol use status and cigarette smoking status, all other variables had significant association with prevalence of common mental disorders $(p<0.05)$ (Table 2).

\begin{tabular}{|c|c|c|c|c|c|}
\hline \multicolumn{2}{|c|}{ Variables } & CMD - Non cases n (\%) & CMD cases $n(\%)$ & COR $(95 \% \mathrm{Cl})$ & $p$-Value \\
\hline \multirow{5}{*}{ Age } & $18-27$ & $112(78.9 \%)$ & $30(21.1 \%)$ & 1 & \\
\hline & $28-37$ & $226(74.6 \%)$ & $77(25.4 \%)$ & $1.72(0.79-2.05)$ & 0.325 \\
\hline & $38-47$ & $97(55.7 \%)$ & $77(44.3 \%)$ & $2.96(1.79-4.89)$ & $<0.001$ \\
\hline & $48-57$ & $43(45.3 \%)$ & $52(54.7 \%)$ & $4.52(2.55-7.99)$ & $<0.001^{*}$ \\
\hline & $>57$ & $6(40.0 \%)$ & $9(60.0 \%)$ & $5.60(1.85-16.97)$ & $0.002 *$ \\
\hline \multirow{2}{*}{ Sex } & Male & $267(76.5 \%)$ & $82(23.5 \%)$ & 1 & \\
\hline & Female & $217(57.1 \%)$ & $163(42.9 \%)$ & $2.45(1.78-3.37)$ & $<0.001$ \\
\hline \multirow{4}{*}{ Religion } & Muslim & $153(64.3 \%)$ & $85(35.7 \%)$ & $1.38(0.89-2.15)$ & 0.151 \\
\hline & Orthodox & $205(66.8 \%)$ & $102(33.2 \%)$ & $1.24(0.81-1.90)$ & 0.326 \\
\hline & Protestant & $107(71.3 \%)$ & $43(28.7 \%)$ & 1 & \\
\hline & Others & $19(55.9 \%)$ & $15(44.1 \%)$ & $1.96(0.92-4.23)$ & 0.083 \\
\hline \multirow{5}{*}{ Ethnicity } & Oromo & $187(70.0 \%)$ & $80(30.0 \%)$ & 1 & \\
\hline & Amhara & $140(67.3 \%)$ & $68(32.7 \%)$ & $1.14(0.77-1.69)$ & 0.524 \\
\hline & Keffa & $95(63.8 \%)$ & $54(36.2 \%)$ & $1.33(0.87-2.03)$ & 0.189 \\
\hline & Gurage & $50(68.5 \%)$ & $23(31.5 \%)$ & $1.07(0.62-1.88)$ & 0.799 \\
\hline & Others & $12(37.5 \%)$ & $20(62.5 \%)$ & $3.90(1.82-8.35)$ & $<0.001^{\prime}$ \\
\hline \multirow{4}{*}{ Marital status } & Single & $182(74.3 \%)$ & $63(25.7 \%)$ & 1 & \\
\hline & Married & $225(67.8 \%)$ & $107(32.2 \%)$ & $1.37(0.95-1.94)$ & 0.09 \\
\hline & Divorced and separated & $64(54.2 \%)$ & $54(45.8 \%)$ & $2.44(1.54-3.87)$ & $<0.001$ \\
\hline & Widowed & $13(38.2 \%)$ & $21(61.8 \%)$ & $4.67(2.21-9.87)$ & $<0.001$ \\
\hline \multirow{5}{*}{ Educational status } & Unable to read and write & $22(40.7 \%)$ & $32(59.3 \%)$ & $4.19(2.20-7.99)$ & $<0.001$ \\
\hline & Able to read and write & $70(59.8 \%)$ & $47(40.2 \%)$ & $1.94(1.17-3.21)$ & $0.011^{*}$ \\
\hline & Primary school & $126(70.4 \%)$ & $53(29.6 \%)$ & $1.21(0.76-1.95)$ & 0.423 \\
\hline & Secondary school & $142(67.0 \%)$ & $70(33.0 \%)$ & $1.42(0.91-2.23)$ & 0.125 \\
\hline & College and above & $124(74.3 \%)$ & $43(25.7 \%)$ & 1 & \\
\hline \multirow{6}{*}{ Occupational status } & Employed & $239(77.3 \%)$ & $70(27.7 \%)$ & 1 & \\
\hline & Self-employed & $150(63.6 \%)$ & $86(36.4 \%)$ & $1.96(1.34-2.85)$ & $<0.001^{*}$ \\
\hline & Student & $18(62.1 \%)$ & $11(37.9 \%)$ & $2.09(0.94-4.63)$ & 0.07 \\
\hline & Housewife & $26(46.4 \%)$ & $30(53.6 \%)$ & $3.94(2.19-7.10)$ & $<0.001^{*}$ \\
\hline & Unemployed & $38(58.5 \%)$ & $27(41.5 \%)$ & $2.43(1.38-4.25)$ & $0.002^{*}$ \\
\hline & Others & $13(38.2 \%)$ & $21(61.8 \%)$ & $5.52(2.63-11.57)$ & $<0.001$ \\
\hline \multirow{4}{*}{ Gross monthly family income (ETB) } & $100-800$ & $131(60.4 \%)$ & $86(39.6 \%)$ & $1.58(1.04-2.41)$ & $0.032^{*}$ \\
\hline & $801-1500$ & $109(69.9 \%)$ & $47(30.1 \%)$ & $1.04(0.65-1.66)$ & 0.865 \\
\hline & $1501-3000$ & $128(70.7 \%)$ & $53(29.3 \%)$ & 1 & \\
\hline & $>3000$ & $116(66.3 \%)$ & $59(33.7 \%)$ & $1.23(0.78-1.92)$ & 0.368 \\
\hline \multirow{2}{*}{ Family size } & $<3.6$ & $292(72.3 \%)$ & $112(27.7 \%)$ & 1 & \\
\hline & $>3.6$ & $192(59.1 \%)$ & $133(40.9 \%)$ & $1.81(1.32-2.46)$ & $<0.001^{*}$ \\
\hline \multirow{2}{*}{ Khat use } & Yes & $168(60.2 \%)$ & $111(39.8 \%)$ & $1.56(1.14-2.13)$ & $0.006^{*}$ \\
\hline & No & $316(70.2 \%)$ & $134(29.8 \%)$ & 1 & \\
\hline \multirow{2}{*}{ Alcohol use } & Yes & $110(63.2 \%)$ & $64(36.8 \%)$ & $1.20(0.84-1.72)$ & 0.31 \\
\hline & No & $374(67.4 \%)$ & $181(32.6 \%)$ & 1 & \\
\hline \multirow{2}{*}{ Cigarette smoking } & Yes & $53(57.6 \%)$ & $39(42.4 \%)$ & $1.54(0.99-2.40)$ & 0.058 \\
\hline & No & $431(67.7 \%)$ & $206(32.3 \%)$ & 1 & \\
\hline \multirow{3}{*}{ Level of social support } & Poor & $195(58.7 \%)$ & $137(41.3 \%)$ & $2.61(1.10-6.18)$ & $0.029^{*}$ \\
\hline & Moderate & $263(72.3 \%)$ & $101(27.7 \%)$ & $1.43(0.60-3.39)$ & 0.421 \\
\hline & Strong & $26(78.8 \%)$ & $7(21.2 \%)$ & 1 & \\
\hline \multirow{2}{*}{ Chronic physical illness } & Yes & $81(51.6 \%)$ & $76(48.4 \%)$ & $2.24(1.56-3.21)$ & $<0.001$ \\
\hline & No & $403(70.5 \%)$ & $169(29.5 \%)$ & 1 & \\
\hline
\end{tabular}

Table 2: Prevalence of common mental disorders and associated factors among residents of Jimma town, March, 2015. 
Citation: Kerebih H, Soboka M (2016) Prevalence of Common Mental Disorders and Associated Factors among Residents of Jimma Town, Southwest Ethiopia. J Psychiatry 19: 373 doi:10.4172/2378-5756.1000373

Page 5 of 7

\begin{tabular}{|c|c|c|c|c|c|}
\hline \multicolumn{2}{|c|}{ Variables } & COR $(95 \% \mathrm{Cl})$ & $p$-Value & AOR $(95 \% \mathrm{Cl})$ & $p$-Value \\
\hline \multirow{6}{*}{ Age } & $18-27$ & 1 & & 1 & \\
\hline & $28-37$ & $1.72(0.79-2.05)$ & 0.325 & $1.36(0.75-2.45)$ & 0.314 \\
\hline & $38-47$ & $2.96(1.79-4.89)$ & $<0.001$ & $4.04(2.07-7.91)$ & $<0.001^{*}$ \\
\hline & $48-57$ & $4.52(2.55-7.99)$ & $<0.001$ & 6.79(3.14-14.68) & $<0.001^{*}$ \\
\hline & $>57$ & $5.60(1.85-16.97)$ & 0.002 & $7.37(2.03-26.80)$ & $0.002^{*}$ \\
\hline & Male & 1 & & 1 & \\
\hline \multirow{2}{*}{ Sex } & Female & $2.45(1.78-3.37)$ & $<0.001$ & $2.09(1.42-3.09)$ & $<0.001^{*}$ \\
\hline & Muslim & $1.38(0.89-2.15)$ & 0.151 & $1.47(0.84-2.57)$ & 0.175 \\
\hline \multirow{4}{*}{ Religion } & Orthodox & $1.24(0.81-1.90)$ & 0.326 & $1.26(0.76-2.10)$ & 0.375 \\
\hline & Protestant & 1 & & 1 & \\
\hline & Others & $1.96(0.92-4.23)$ & 0.083 & $1.98(0.79-4.97)$ & 0.146 \\
\hline & Oromo & 1 & & 1 & \\
\hline \multirow{4}{*}{ Ethnicity } & Amhara & $1.14(0.77-1.69)$ & 0.524 & $2.41(1.31-3.50)$ & $0.002^{*}$ \\
\hline & Keffa & $1.33(0.87-2.03)$ & 0.189 & $3.32(1.89-5.82)$ & $<0.001^{*}$ \\
\hline & Gurage & $1.07(0.62-1.88)$ & 0.799 & $2.26(1.13-4.53)$ & $0.022^{*}$ \\
\hline & Others & $3.90(1.82-8.35)$ & $<0.001$ & $7.36(2.91-18.63)$ & $<0.001^{*}$ \\
\hline \multirow{5}{*}{ Marital status } & Single & 1 & & 1 & \\
\hline & Married & $1.37(0.95-1.94)$ & 0.09 & $0.59(0.36-0.97)$ & $0.037^{*}$ \\
\hline & Divorced and separated & $2.44(1.54-3.87)$ & $<0.001$ & $1.30(0.73-2.33)$ & 0.371 \\
\hline & Widowed & $4.67(2.21-9.87)$ & $<0.001$ & $1.29(0.48-3.49)$ & 0.608 \\
\hline & Unable to read and write & $4.19(2.20-7.99)$ & $<0.001$ & $3.91(1.65-9.26)$ & $0.002^{*}$ \\
\hline \multirow{5}{*}{ Educational status } & Able to read and write & $1.94(1.17-3.21)$ & 0.011 & $1.05(0.54-2.05)$ & 0.881 \\
\hline & Primary school & $1.21(0.76-1.95)$ & 0.423 & $1.05(0.57-1.93)$ & 0.883 \\
\hline & Secondary school & $1.42(0.91-2.23)$ & 0.125 & $1.59(0.90-2.82)$ & 0.111 \\
\hline & College and above & 1 & & 1 & \\
\hline & Employed & 1 & & 1 & \\
\hline \multirow{5}{*}{ Occupational status } & Self-employed & $1.96(1.34-2.85)$ & $<0.001$ & $1.14(0.69-1.90)$ & 0.613 \\
\hline & Student & $2.09(0.94-4.63)$ & 0.07 & $1.94(0.74-5.06)$ & 0.176 \\
\hline & Housewife & $3.94(2.19-7.10)$ & $<0.001$ & $3.37(1.59-7.13)$ & $0.001^{*}$ \\
\hline & Unemployed & $2.43(1.38-4.25)$ & 0.002 & $1.43(0.69-2.97)$ & 0.333 \\
\hline & Others & $5.52(2.63-11.57)$ & $<0.001$ & $4.97(1.93-12.82)$ & $0.001^{*}$ \\
\hline \multirow{4}{*}{$\begin{array}{l}\text { Gross monthly family income } \\
\text { (ETB) }\end{array}$} & $100-800$ & $1.58(1.04-2.41)$ & 0.032 & $1.08(0.62-1.86)$ & 0.789 \\
\hline & $801-1500$ & $1.04(0.65-1.66)$ & 0.865 & $0.96(0.54-1.70)$ & 0.897 \\
\hline & $1501-3000$ & 1 & & 1 & \\
\hline & $>3000$ & $1.23(0.78-1.92)$ & 0.368 & $1.37(0.79-2.38)$ & 0.269 \\
\hline \multirow{2}{*}{ Family size } & $<3.6$ & 1 & & 1 & \\
\hline & $>3.6$ & $1.81(1.32-2.46)$ & $<0.001$ & $1.31(0.89-1.94)$ & 0.169 \\
\hline \multirow{2}{*}{ Khat use } & Yes & $1.56(1.14-2.13)$ & 0.006 & $1.64(1.09-2.46)$ & $0.018^{*}$ \\
\hline & No & 1 & & 1 & \\
\hline \multirow{2}{*}{ Cigarette smoking } & Yes & $1.54(0.99-2.40)$ & 0.058 & $1.07(0.62-1.86)$ & 0.814 \\
\hline & No & 1 & & 1 & \\
\hline \multirow{3}{*}{ Level of social support } & Poor & $2.61(1.10-6.18)$ & 0.029 & 2.74(0.99-7.57) & 0.052 \\
\hline & Moderate & $1.43(0.60-3.39)$ & 0.421 & $2.01(0.72-5.58)$ & 0.182 \\
\hline & Strong & 1 & & 1 & \\
\hline \multirow{2}{*}{ Chronic physical illness } & Yes & $2.24(1.56-3.21)$ & $<0.001$ & $2.51(1.62-3.89)$ & $<0.001^{*}$ \\
\hline & No & 1 & & 1 & \\
\hline
\end{tabular}

Table 3: Multivariate logistic regression analysis of common mental disorders and associated factors among residents of Jimma town, March, 2015.

After adjusting of confounding factors on multivariate logistic regression analysis, it was found that respondents with age group of 38-47 years had 4 times higher prevalence of common mental disorders than younger ages, $18-27$ year $(\mathrm{AOR}=4.04,95 \% \mathrm{CI}: 2.07$ $7.91)$. Whereas the older age groups of $48-57$ year and $>57$ year were 6.8 times $(\mathrm{AOR}=6.79,95 \% \mathrm{CI}: 3.14-14.68)$ and 7.4 times $(\mathrm{AOR}=7.37$, 95\% CI: 2.03-26.80) affected by common mental disorders than $18-27$ year groups of respondents. The odds of having CMD was 2.1 times (AOR=2.09, 95\% CI: 1.42-3.09) higher in females than in males. The odds of CMD was 2.4 times (AOR=2.41, 95\% CI: 1.31-3.50) higher in Amhara respondents, 3.3 times ( $\mathrm{AOR}=3.32$, 95\% CI: 1.89-5.82) higher in keffa, 2.3 times ( $\mathrm{AOR}=2.26,95 \% \mathrm{CI}: 1.13-4.53)$ higher in Gurage and 7.4 times $(\mathrm{AOR}=7.36,95 \%, \mathrm{CI}: 2.91-18.63)$ higher in other ethnicities such as, Tigre, Wolayita, Yem, Hadiya and Dawuro compared to Oromo 
ethnicity. Married respondents were $41 \%(\mathrm{AOR}=0.59$, 95\% CI: 0.36 0.97) less affected by CMD than single respondents. Respondents who were unable to read and write in educational status had about 4 times (AOR=3.91, 95\% CI: 1.65-9.26) higher risk of CMD than respondents with college and above educational status. The odds of having CMD among housewives was 3.4 times ( $\mathrm{AOR}=3.37,95 \% \mathrm{CI}: 1.59-7.13$ ) higher than employed workers while the odds of having CMD among Pensioners, Farmers, Daily laborers and House servants was about 5 times (AOR=4.97, 95\% CI: 1.93-12.82) higher than employed workers.

Current khat user were having 1.6 times (AOR=1.64, 95\% CI: 1.09 2.46) higher $\mathrm{CMD}$ than non-users and respondents having chronic physical illness had 2.5 times (AOR=2.51, 95\% CI: 1.62-3.89) higher prevalence of CMD than those without the illness (Table 3)

\section{Discussion}

This study aimed to assess, the point prevalence of common mental disorders and it was found $33.6 \%$. It was similar with study findings from North East Ethiopia which reported $32.4 \%$ prevalence rate of common mental disorders and used similar screening tool and cut-off point [14]. It was also in agreement with a community based study from South Africa with a prevalence of common mental disorders $34.9 \%$ [10]. However, the later used a cut-off point of $\geq 9$ in SRQ-20 items while in this study a cutoff point of $\geq 8$ was used. The prevalence of the current study was found to be higher from similar community based studies in Kenya where the prevalence of common mental disorders was $10.8 \%$ and in Ethiopia, Butajira (17\%). The reasons could be the Clinical Interview Schedule-Revised (CIS-R) was used in Kenyan study and the Butajira study used a cut-off point of $\geq 11$ of the SRQ-20 items which makes the prevalence of common mental disorders lower $[9,10]$.

The study demonstrated that there was higher prevalence of common mental disorders among women than men. This finding agrees with different study findings in various countries such as in Ethiopia [12,13], South Africa [10] and Greece [6]. The higher prevalence among women could be explained by considerable level of stress and suffering faced by women due to heavier burden of social and household responsibilities. In the current study the prevalence of common mental disorders was higher in older age group which was supported by similar community based studies from Ethiopia and Kenya $[9,13]$. In the current study being married was independently associated as a protective factor from common mental disorders which was similar with a study finding from a general population survey in Greece [6]. But this is against from a study finding from India in which being married had increased risks for common mental disorders than singles [21]. The discrepancy might be due to the use of different tools to assess common mental disorders SRQ-20 for this study and CIS-R for the Indian study and a difference in study population in which the Indian study population was comprised of only women participants. Similar with study findings in South Africa [10], Kenya [9], Greece [6] and Ethiopia [12-14], unable to read and write was associated with increased risk of common mental disorders in this study. Regarding occupational status, being housewife was associated with increased risk of common mental disorders while many previous studies indicated higher prevalence of common mental disorders in unemployed respondents $[6,10,13]$. The probable reasons could be that many of the housewives might be unemployed but are in charge of many household responsibilities which may predispose them to emotional and physical strain.

Current khat use was associated with increased risk for having common mental disorders. This finding was in agreement with other study results from North East Ethiopia and Southwest Ethiopia [12,22].
Respondents who reported of having chronic physical illness were found to have increased risk for common mental disorders than their counter parts. Similar study results were obtained from a community based study in Kenya and Ethiopia where poor physical health condition was reported to increase the risk of the disorders $[9,12]$.

The use of cross sectional study design, in which it is difficult to identify whether the outcome variable influenced the predictors or the predictors influenced the outcome variable, recall bias and social desirability bias due to the nature of measurement tool and use of interviewer administered questionnaire to obtain information could be considered as limitation of this study.

\section{Conclusions}

The result of the current study showed a higher prevalence of common mental disorders among residents of Jimma town. The prevalence of common mental disorders was found higher in females, older age groups, in housewives, in respondents who currently chew khat and in those with chronic physical illness. Marriage was found to be a protective factor from common mental disorders. Therefore, it is recommended that mental health services have to be expand to the community level with wide scale mental health training of general health professionals particularly primary health care workers including the urban health extension workers who have direct contact with the community. By doing so, appropriate intervention will be taken on factors contributing to common mental disorders.

\section{Conflict of interest}

Both authors declared no conflict of interest.

\section{Authors' Contribution}

HK has contributed in idea conception, topic selection, write up of proposal for funding, data analysis, write up of results \& the manuscript. MS has contributed idea generation in title selection, contributed in organizing literatures important to the study, commented both proposal draft and result as well as manuscript write ups.

\section{Acknowledgment}

The authors wish to Acknowledge Jimma University for supporting the study financially. The authors would also like to especially thank study participants for giving their precious time and provided information.

\section{References}

1. World Health Organization (2001) The world health report 2001 - Mental Health New Understanding, New Hope.

2. WHO (2013) Investing in mental health: Evidence for Action.

3. Eaton WW, Martins SS, Nestadt G, Bienvenu OJ, Clarke D, et al. (2008) The burden of mental disorders. Epidemiol Rev 30: 1-14.

4. Kessler RC, Merikangas KR, Wang PS (2007) Prevalence, Comorbidity, and Service Utilization for Mood Disorders in the United States at the Beginning of the Twenty-first Century. Annu Rev Clin Psychol 3: 137-158.

5. Baumeister $\mathrm{H}$, Härter $\mathrm{M}$ (2007) Prevalence of mental disorders based on general population surveys. Soc Psychiatry Psychiatr Epidemiol 42: 537-546.

6. Skapinakis P, Bellos S, Koupidis S, Grammatikopoulo L, Theodorakis PN, et al. (2013) Prevalence and socio demographic associations of common mental disorders in a nationally representative sample of the general population of Greece. BMC Psychiatry 13: 163

7. Johansson R, Carlbring P, Heedman A, Paxling B, Andersson G (2013) Depression, anxiety and their comorbidity in the Swedish general population point prevalence and the effect on health-related quality of life. PeerJ 1: e98.

8. Kawakami N, Takeshima $\mathrm{T}$, Ono $\mathrm{Y}, \mathrm{Uda} \mathrm{H}$, Hata $\mathrm{Y}$, et al. Twelve-month prevalence, severity, and treatment of common mental disorders in communities in Japan: preliminary finding from the World Mental Health Japan Survey 2002 2003. Psychiatry Clin Neurosci 59: 441-452. 
Citation: Kerebih H, Soboka M (2016) Prevalence of Common Mental Disorders and Associated Factors among Residents of Jimma Town, Southwest Ethiopia. J Psychiatry 19: 373 doi:10.4172/2378-5756.1000373

9. Jenkins Njenga F, Okonji M, Kigamwa P, Baraza M, et al. Prevalence of Common Mental Disorders in a Rural District of Kenya, and Socio-Demographic Risk Factors. Int J Environ Res Public Health 9: 1810-1819.

10. Havenaar MJ, Geerlings MI, Vivian L, Collinson M, Robertson B (2008) Common mental health problems in historically disadvantaged urban and rural communities in South Africa: prevalence and risk factors. Soc Psychiatry Psychiatr Epidemiol 43: 209-215.

11. Gureje O, Lasebikan VO, Kola L, Makanjuola VA (2006) Lifetime and 12-month prevalence of mental disorders in the Nigerian Survey of Mental Health and Well-Being. Br J Psychiatry 88:465-471.

12. Alem A, Kebede D, Woldesemiat G, Jacobsson L, Kullgren G (1999) The prevalence and socio-demographic correlates of mental distress in Butajira, Ethiopia. Acta Psychiatr Scand Suppl 397: 48-55.

13. Kebede D, Alem A, Rashid E (1999) The prevalence and socio-demographic correlates of mental distress in Addis Ababa, Ethiopia. Acta Psychiatr Scand Suppl 397: 5-10.

14. Yimam K, Kebede $Y$ and Azale T (2014) Prevalence of Common Menta Disorders and Associated Factors among Adults in Kombolcha Town, Northeast Ethiopia. J Depress Anxiety S1: 007
15. Cyhlarova E, McCulloch A, McGuffin P, Wykes T (2010) Economic burden of mental illness cannot be tackled without research investment. Mental Health Foundation.

16. Bloom DE, Cafiero ET, Jané-Llopis E, Abrahams-Gessel S, Bloom LR, et al. (2011) The Global Economic Burden of Non communicable Diseases. Geneva: World Economic Forum.

17. Sadock BJ, Sadock VA, Ruiz P (2009) Kaplan and Sadock's Comprehensive Textbook of Psychiatry. (9th Edn) Lippincott Williams \& Wilkins, USA.

18. Central Statistical Agency (2007) Population and Housing Census ReportCountry-2007. Central Statistical Agency.

19. World Health Organization (1994) A User's Guide to the Self Reporting Questionnaire (SRQ)

20. Harpham T, Reichenheim M, Oser R, Thomas E, Hamid N, et al. Measuring mental health in a cost-effective manner. Health Policy Plan 18: 344-349.

21. Patel V, Kirkwood BR, Pednekar S, Weiss H, Mabey D (2006) Risk factors for common mental disorders in women. Br J Psychiatry 189: 547-555.

22. Damena T, Mossie A, Tesfaye M (2011) Khat Chewing and Mental Distress: A Community Based Study, in Jimma City, Southwestern Ethiopia. Ethiop J Health Sci 21: 37-45. 